\title{
Erratum to: Abstraction and Insight: Building Better Conceptual Systems to Support More Effective Social Change
}

\author{
Steven E. Wallis ${ }^{1,2}$
}

Published online: 31 July 2017

(C) Springer Science+Business Media B.V. 2017

\section{Erratum to: Found Sci (2015) 20:189-198 DOI 10.1007/s10699-014-9359-x}

This article was unintentionally published twice in this journal, by the same authors. Following should be considered the version of record and used for citation purposes: "Steven E. Wallis, Abstraction and Insight: Building Better Conceptual Systems to Support More Effective Social Change, Foundations of Science, Volume 19, Issue 4, pages 353-362, DOI:10.1007/s10699-014-9344-4". The duplicate "Steven E. Wallis, Abstraction and Insight: Building Better Conceptual Systems to Support More Effective Social Change, Foundations of Science, Volume 20, Issue 2, pages 189-198, DOI:10.1007/ s10699-014-9359-x" is to be ignored. Diederik Aerts, Editor-in-Chief I Springer, apologizes to the readers of the journal for any inconvenience that this error in the publication process might have caused.

The online version of the original article can be found under doi:10.1007/s10699-014-9359-x.

Steven E. Wallis

swallis@projectfast.org

1 Foundation for the Advancement of Social Theory, Petaluma, CA, USA

2 Capella University, Minneapolis, MN, USA 